\title{
Gleichenia linearis Burm. Leaf extract as corrosion inhibitor of mild steel in hydrochloric acid medium
}

\author{
Y. Stiadi,* M. Efdi, H. Aziz and Emriadi \\ Department of Chemistry, Faculty of Mathematics and Natural Sciences, Universitas \\ Andalas, Padang, 25163, Indonesia \\ *E-mail: yenistiadi@sci.unand.ac.id
}

\begin{abstract}
Resam or Gleichenia linearis Burm. is one of a wild shrub that thrives in Indonesia forests. Using Gleichenia linearis Burm. leaf extract as corrosion inhibitor of mild steel in $1 \mathrm{M} \mathrm{HCl}$ investigated by weight loss, potentiodynamic polarization, Fourier-transform infrared spectroscopy, and scanning electron microscopy methods. The results prove that the chemical content of Gleichenia linearis Burm. leaf extract can inhibit the corrosion rate of mild steel and exhibit high inhibition efficiency. The use of $4 \mathrm{~g} / \mathrm{L}$ Gleichenia linearis Burm. leaf extract in $1 \mathrm{M}$ hydrochloric acid medium has inhibited the corrosion of mild steel with an inhibition efficiency reaching $84.54 \%$. The adsorption of this extract on the surface of mild steel follows Freundlich adsorption isotherm. Potentiodynamic polarization measurements showed that Gleichenia linearis Burm. leaf extract was a type of mixed inhibitor with more anodic effectiveness. The results of the analysis of corrosion products, extracts, and mild steel surfaces show different infrared spectra between extracts and corrosion products. The mild steel surface is covered by the extract and shows a smoother, flat surface. Kinetic and thermodynamic parameters indicate that the extraction occurs spontaneously on mild steel surfaces. Corrosion inhibition of Gleichenia linearis Burm. leaf extract occurs due to the physical adsorption process on the steel surface.
\end{abstract}

Keywords: Gleichenia linearis Burm., weight loss, potentiodynamic polarization, corrosion inhibitor, hydrochloric acid.

Received: September 20, 2020. Published: December 7, 2020

doi: $\underline{10.17675 / 2305-6894-2020-9-4-20}$

\section{Introduction}

In various industrial processes such as industrial acid cleaning, cooling systems, chemical and electrochemical etching, acid crust removal, and oil acidification, acidic solutions are often used. Hydrochloric acid and sulfuric acid are often used as cleaning agents in several industries to remove unwanted oxide layers and corrosion products. Hydrochloric acid is preferred because it is highly efficient and economical in comparison to other acids [1-10]. Corrosion inhibitors are generally used in the process to prevent the dissolution of iron or iron alloys. However, various inhibitors are harmful, which leads to the aim of most studies to obtain environmentally friendly inhibitors. Most natural inhibitors are derived from natural products, especially plants that can be decomposed, non-toxic, and cheaper $[1,6,7$, 
9-11]. The inhibitor itself is a small amount of chemical added to the corrosive environment [3].

Much research has been conducted to study the effect of natural inhibitors on the corrosion rate of steel in an acidic medium. The compounds contained in natural inhibitors can be absorbed onto the surface of the steel while blocking the surface against corrosive attacks. This would naturally cause the corrosion rate to reduce. Adsorption of organic molecules from inhibitors on metals or metal interfaces and solutions can pass through several adsorption types such as electrostatic attraction of charge from molecules and metals, and phi electrons and metal interactions $[1,2,9,11]$.

Various organic compounds have been extracted from plant parts and plant-derived side products that have been used in the field of corrosion inhibition. Organic ingredients have biodegradable properties and are easily attained. Many natural ingredients have been tested to function as corrosion inhibitors of steel in the acidic medium [2]. The organic material originates from various leaf extracts such as Toona sinensis [1], Thymus vulgaris [3], Pandanus tectorius plant [7], Piper guineense [9], Passiflora foetida [10], Ginkgo [12], Manihot esculenta [13], fenugreek [14], Nauclea latifolia [15], and Nicotiana tabacum [16]. The compounds of the fruit peel that have been studied are orange peel [14], Cucumis sativus [17], mango and orange, passion fruit and cashew [18], coffee [19], Musa paradisiac [20], Theobroma cacao [21, 22], and many others, while compounds are extracted from plant seeds such as Nigella sativa L. [8], Retama monosperma (L.) Boiss. [23], Psidium guajava [24], Ceiba pentandra [25], Strychnos nuxvomica [26], Foeniculum vulgare Mill [27], Mucuna pruriens [28], and Mangifera odorata Griff [29].

In this study, the potential and the effectiveness of Gleichenia linearis Burm. leaf extract (GLLE) which was in the corrosive environment of hydrochloric acid to the corrosion rate of mild steel were studied. Resam (Gleichenia linearis Burm.) can be found in almost all tropical and subtropical regions in Asia and the Pacific. Its habitat is shady and humid cliffs starting at an altitude of $200 \mathrm{~m}$ to $1500 \mathrm{~m}$ above sea level. Utilization of GLLE as mild steel corrosion inhibitor was studied by weight loss, an electrochemical method, Fourier transform infrared (FT-IR) and scanning electron microscope (SEM).

\section{Experimental}

\subsection{Preparation of mild steel specimens}

The steel specimens used for the study are sheet, each with a composition (\% by weight); C: 0.189, Mn: 0.141, Si: 0.0715, P: 0.0149, Se: 0.019, Cr: 0.0018, Ni: 0.001, and the remaining would be Fe. The steel sheet was cut mechanically to form several coupons, each with dimensions of $3.0 \times 2.0 \times 0.1 \mathrm{~cm}$, given a hole at the top to provide space to place the hooks. Each coupon is cleaned with emery paper and then mixed with ethanol, dipped in acetone and left to dry, and stored in a desiccator. The reagents used in making the solutions for the study were Analar grade and distilled water. The $1 \mathrm{M} \mathrm{HCl}$ solution is used as a blank solution. 


\subsection{Preparation of leaf extract}

Fresh leaves of the Gleichenia linearis Burm. plant were collected from Ulu Gadut forest, Padang city, West Sumatra Indonesia. Leaves of Gleichenia linearis Burm. were dried and ground to fine powder. Approximately $500 \mathrm{~g}$ of powder was macerated in $1500 \mathrm{~mL}$ of methanol for 4 days. The results of maceration were filtered. The filtrate is evaporated using a rotary evaporator so that the dark green concentrated extract is obtained. The extract from this leaf was weighed $2 \mathrm{~g}$ and dissolved with distilled water in a $100 \mathrm{~mL}$ volumetric flask to obtain an extract solution with a concentration of $20 \mathrm{~g} \cdot \mathrm{L}^{-1}$. This solution was used as a stock solution.

\section{3. $L C-M S / M S$ analysis}

The analysis of GLLE was performed by the LC-MS/MS system composed of instrument Waters, an UPLC Acquity I-Class type combined with an MS/MS type XEVO G2-S QTOF detector. Chromatographic separation was achieved using a Waters Acquity HSS column (T3 $1.8 \mu \mathrm{m}, 2.1 \mathrm{~mm} \times 100 \mathrm{~mm}$ ). The column temperature was set to $40^{\circ} \mathrm{C}$. The mobile phase system consisted of two eluents, A ( $0.1 \%$ formic acid in water) and B $(0.1 \%$ formic acid in acetonitrile). The flow rate is adjusted to $0.60 \mathrm{~mL} /$ minute with an injection volume of 2$5 \mathrm{~mL}$. The Tof MSE mass spectrometer has ESI (-) and ESI (+) electrospray ionization sources. The ESI source operated with the following parameters: capillary voltage $2.0 \mathrm{kV}$; cone voltage $40 \mathrm{~V}$; low $\mathrm{CE} 6 \mathrm{~V}$, high CE Ramp 15-40 V; source temperature $120^{\circ} \mathrm{C}$; desolvation gas flow $1000 \mathrm{~L} / \mathrm{h}$; desolvation temperature $550^{\circ} \mathrm{C}$; gas cone $50 \mathrm{~L} / \mathrm{h}$; and acquisition range 50-1200 Da.

\subsection{Weight loss method}

The weighted mild steel sheet $\left(m_{1}\right)$ was immersed in $50 \mathrm{~mL}$ of $1 \mathrm{M} \mathrm{HCl}$ corrosive solution with and without the addition of various GLLE concentrations. Immersion temperature variations were carried out at $30,40,50$ and $60^{\circ} \mathrm{C}$ for 7 hours using a water bath. After the mild steel has been soaked for 7 hours, the steel is cleaned with a brush, rinsed and dried in the oven. After dry, light steel is weighed $\left(m_{2}\right)$. From the data of weight loss calculated the corrosion rate $(C R)$ and inhibition efficiency $(I E)$ can be calculated using the following equations:

$$
C R=\frac{m_{1}-m_{2}}{A t}
$$

and

$$
I E \%=\frac{C R_{1}-C R_{2}}{C R_{1}} \cdot 100
$$


where $m_{1}$ and $m_{2}$ are weight before and after immersion (mg), $A$ is surface area $\left(\mathrm{cm}^{2}\right), t$ is immersion time (hours), $C R_{1}$ and $C R_{2}\left(\mathrm{mg} \cdot \mathrm{cm}^{-2} \cdot \mathrm{h}^{-1}\right)$ are corrosion rate in the absence and presence of inhibitor, respectively $[5,7,29,30]$.

\subsection{Potentiodynamic polarization method}

The conventional three-electrode system was used for measurements using the potentiodynamic polarization method that utilized the eDAQ 466 potentiostats. Mild steel specimens were used as working electrodes, each having a surface area of $0.0214 \mathrm{~cm}^{2}$. The other two electrodes were $\mathrm{Pt}$ and $\mathrm{Ag} \mid \mathrm{AgCl}$ electrodes, each of which functions as an auxiliary and reference electrode. Potentiodynamic polarization measurements were carried out in $1 \mathrm{M} \mathrm{HCl}$ without and with GLLE with different concentrations in the potential range potential of $-800 \mathrm{mV}$ to $-100 \mathrm{mV}$. All electrochemical studies were carried out at room temperature and scan rate $1 \mathrm{mV} / \mathrm{s}$.

\subsection{FT-IR measurements}

The FT-IR spectrum was recorded for GLLE inhibitor with a frequency ranging from 4000 to $400 \mathrm{~cm}^{-1}$ by Fourier transforms infrared spectrophotometer (Nicolet IS10 FT-IR, Thermo Scientific).

\subsection{SEM analysis}

Mild steel sheets were immersed in $1 \mathrm{M}$ hydrochloric acid without and with GLLE for 6 days. The mild steel was then dried and analyzed by scanning electron microscopy (SEM).

\section{Results and discussion}

\subsection{LC-MS/MS analysis}

The results of the chemical content analysis of GLLE are presented in Table 1 and show that the methanol extract content of Gleichenia linearis Burm. leaves is dominated by flavonoids and phenolics. Besides, there is also a small number of alkaloids in the extract. The chemical content of GLLE indicates that this plant's leaves have high efficiency in inhibiting steel corrosion.

Table 1. The main chemical compounds in Gleichenia linearis Burm. leaf extract.

\begin{tabular}{cc}
\hline Compounds & Percentage, \% \\
\hline Kaempferol-3-gentiobiose & 28.48 \\
Kaempferol & 21.37 \\
3,5,7,2',6'-Hydroxyplavone 5-2'-O- $\beta$-D- \\
$\begin{array}{c}\text { glucopyranoside } \\
\text { Quercetin-3'-O-glucoside }\end{array}$ & 10.19 \\
\hline
\end{tabular}


Compounds

Luteolin-7,4'-di-O- $\beta$-D-glucopyranoside

Buddlenoid A

Maltol

Sophoraflavonoloside

Leucodelphinidin

2,6-Dihydroxybenzoic acid

Epiafzelechin

Radicamine B

Others

\section{Percentage, \%}

5.74

2.26

2.08

2.20

1.31

1.20

0.84

0.10

17.47

These compounds will interact with the mild steel surface to form a barrier layer on mild steel surfaces. The interaction of secondary metabolites contained in extracts of Gleichenia linearis Burm. with steel can be further explained by several methods of analysis.

\subsection{Weight loss measurements}

The corrosion rate that occurs on mild steel surfaces is determined by the method of weight loss. This method identifies the effect of using leaf extract of Gleichenia linearis Burm. on the corrosion rate in mild steel in $1 \mathrm{M} \mathrm{HCl}$ solution. The inhibition of corrosion rate is characterized by smaller steel weight loss by adding GLLE to $1 \mathrm{M} \mathrm{HCl}$ solution when comparing to heavy loss (without the extract).

The increasing concentration of GLLE in the $\mathrm{HCl}$ medium caused a loss of mild steel weight. Reduced weight loss will cause steel corrosion rates to decrease and increase inhibition efficiency. Increased inhibition efficiency is primarily caused by the presence of the steel surface parts that can adsorb GLLE.

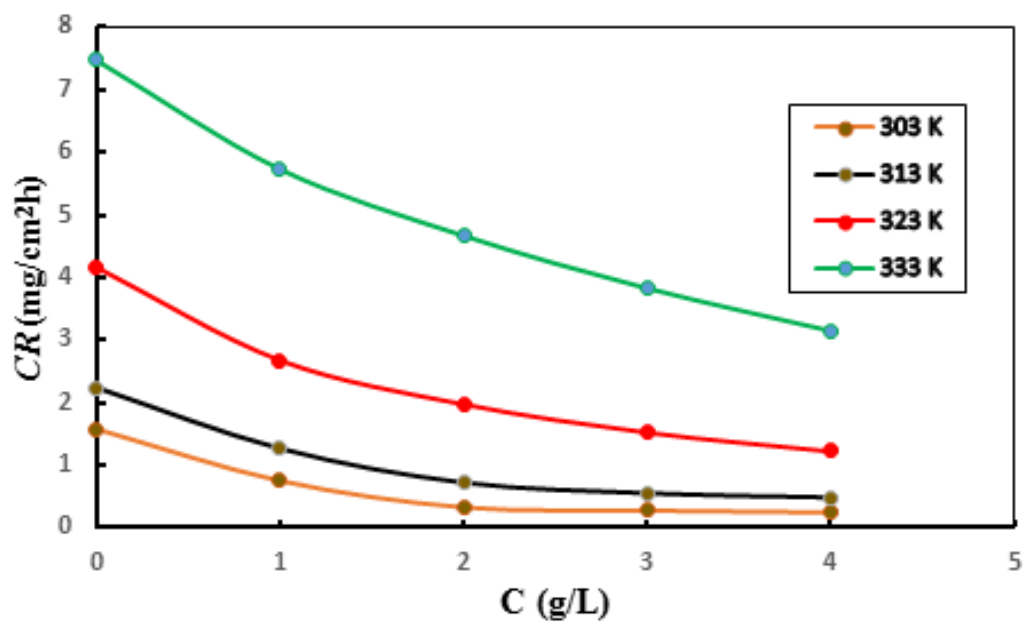

Figure 1. Corrosion rate of mild steel with various concentrations of GLLE in $1 \mathrm{M} \mathrm{HCl}$. 
Regarding the immersion of mild steel in hydrochloric acid medium, the corrosion rate of mild steel increases with increasing temperature. The increased temperature will increase the kinetic energy of particles that can cause corrosion rate to be even greater. Although in the medium there is GLLE, it turns out that the decrease in inhibition efficiency still occurs when the temperature is raised. An increase in temperature can cause the desorption of the chemical content of inhibitors from the steel surface, due to the reduced strength of the adsorption process at higher temperatures [2].

Inhibition efficiency is a percentage reduction in corrosion rate due to the addition of inhibitors and determined using equation $2[10,30]$. In other words, the value of inhibition efficiency is the ability of inhibitors, in this case, the GLLE to resist corrosion of mild steel. Table 2 shows the presented changes in inhibition efficiency on the addition of GLLE into the corrosive medium of hydrochloric acid at various temperatures.

Table 2. The relationship of mild steel corrosion inhibition efficiency and GLLE concentration in $1 \mathrm{M} \mathrm{HCl}$ solution at various temperatures.

\begin{tabular}{ccccc}
\hline \multirow{2}{*}{$\begin{array}{c}\text { GLLE concentration } \\
(\mathbf{g} / \mathbf{L})\end{array}$} & \multicolumn{4}{c}{ Inhibition Efficiency $(\%)$} \\
\cline { 2 - 5 } & $\mathbf{3 0 3} \mathbf{~ K}$ & $\mathbf{3 1 3 ~ K}$ & $\mathbf{3 2 3} \mathbf{~ K}$ & $\mathbf{3 3 3 ~ K}$ \\
\hline 0 & 0 & 0 & 0 & 0 \\
1 & 52.5 & 43.4 & 35.7 & 23.3 \\
2 & 79.4 & 67.8 & 52.6 & 37.5 \\
3 & 82.6 & 75.3 & 63.5 & 48.8 \\
4 & 84.5 & 78.4 & 70.7 & 57.9 \\
\hline
\end{tabular}

The addition of $4 \mathrm{~g} / \mathrm{L}$ GLLE to the corrosive medium was able to provide inhibition efficiency of $84.5 \%$ at $303 \mathrm{~K}$. The efficiency would be greater if more extracts were added to the medium. This high inhibition efficiency is due to GLLE containing various secondary metabolites. In general, the metabolites contained in the leaves of Gleichenia linearis Burm. can function as steel corrosion inhibitors.

The GLLE will interact with mild steel surfaces to form a protective layer that blocks corrosion reactions by acid solutions. The more extracts added to the medium, the higher the value of the inhibition efficiency produced. However, if the temperature rises the inhibition efficiency decreases though the extract added has been quite high. The reduction in efficiency percentage is greater in the temperature range $323-333 \mathrm{~K}$.

\subsection{Thermodynamic considerations}

The corrosion rate obtained from the measurement of weight loss was used to calculate the activation energy $\left(E_{\mathrm{a}}\right)$ for corrosion of mild steel in a solution of $1 \mathrm{M} \mathrm{HCl}$ in the absence and presence of GLLE at 303-333 K using the Arrhenius equation $[1,2,10]$ : 


$$
C R=A \exp \left(-\frac{E_{\mathrm{a}}}{R T}\right)
$$

where $C R$ is the corrosion rate, $A$ is the pre-exponential factor, $E_{\mathrm{a}}$ is inhibition activation energy $\left(\mathrm{kJ} \cdot \mathrm{mol}^{-1}\right), R$ is the gas molar constant, and $T$ is the temperature $(\mathrm{K})$.

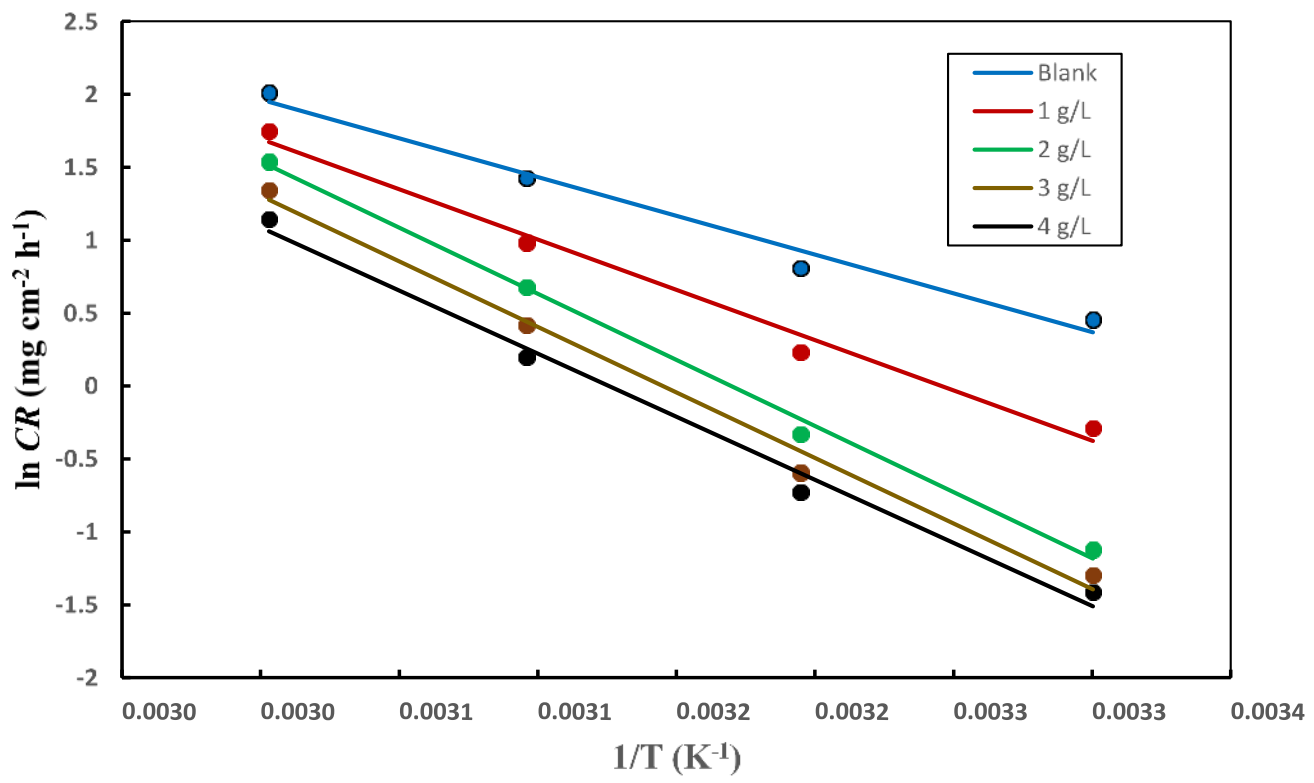

Figure 2. Arrhenius plots for corrosion of steel in $1 \mathrm{M} \mathrm{HCl}$ solution without and with the addition of GLLE at various concentrations.

The activation energy of the mild steel corrosion inhibition process in $\mathrm{HCl}$ medium was determined when in the medium there and without the GLLE at a temperature of 303-333 K. The activation energy value is obtained by using the Arrhenius equation by plotting $1 / T v s$. $\ln C R$ in Figure 2. The slope of the Arrhenius plots straight line equation can be used to determine the inhibition activation energy value by assuming $\ln C R \approx \ln k$. The value of the activation energy of the corrosion process of steel in the hydrochloric acid medium is greater if there is GLLE in the medium. The addition of GLLE always shows activation energy that is greater than the activation energy without the addition of GLLE. Greater concentrations of the extract in the corrosive medium will further block the occurrence of corrosion on the mild steel surface.

At high extract concentrations the wider the areas of mild steel surface is covered or the more extracts are adsorbed on the mild steel surface so that the energy needed for corrosion is greater. Increased activation energy can also indicate that the adsorption of GLLE on mild steel surfaces is physical adsorption which shows the transfer of charge and mass transfer and results in a decrease in the corrosion rate [14,32]. At high extract concentrations, the activation energy of inhibition showed a slight symptom of decline which was still far above the activation energy without extract in the medium. The decrease in 
activation energy that is quite small can occur due to the presence of species that are less obstructed by other species in the adsorption process.

Table 3. Activation energy values without and with the addition of GLLE.

\begin{tabular}{cc}
\hline GLLE in Corrosive Medium $(\mathbf{g} / \mathbf{L})$ & Activation Energy $(\mathbf{k J} / \mathbf{m o l})$ \\
\hline 0 & 44.18 \\
1 & 57.29 \\
2 & 75.36 \\
3 & 74.66 \\
4 & 71.93 \\
\hline
\end{tabular}

Determination of activation enthalpy value $\left(\Delta H^{*}\right)$ and activation entropy $\left(\Delta S^{*}\right)$ inhibition can be calculated using the Arrhenius equation derivative. Enthalpy $\left(\Delta H^{*}\right)$ expresses the energy that accompanies the reaction while entropy shows the degree of particle irregularity in solution. The Arrhenius derivative equation is:

$$
C R=\frac{R T}{N h} \exp \left(\frac{\Delta S^{*}}{R}\right) \exp \left(-\frac{\Delta H^{*}}{R T}\right)
$$

where $N$ is the Avogadro constant $\left(6.023 \cdot 10^{23}\right.$ molecules per mol) and $h$ is the Planck constant $\left(6.63 \cdot 10^{-34} \mathrm{~J} \cdot \mathrm{s}^{-1}\right)$.

Table 4. Enthalpy $\left(\Delta H^{*}\right)$ and entropy $\left(\Delta S^{*}\right)$ value of activation.

\begin{tabular}{ccc}
\hline $\begin{array}{c}\text { GLLE in Corrosive Medium } \\
(\mathbf{g} / \mathbf{L})\end{array}$ & $\begin{array}{c}\Delta \boldsymbol{H}^{*} \\
(\mathbf{k J} / \mathbf{m o l})\end{array}$ & $\begin{array}{c}\Delta \boldsymbol{S}^{*} \\
(\mathbf{J} / \mathbf{m o l})\end{array}$ \\
\hline 0 & 41.54 & -104.88 \\
1 & 54.65 & -67.79 \\
2 & 72.73 & -14.85 \\
3 & 72.03 & -18.90 \\
4 & 69.30 & -28.88 \\
\hline
\end{tabular}

In Table 4 the value of activation enthalpy change $\left(\Delta H^{*}\right)$ obtained is positive and increases with the addition of GLLE concentrations in the medium. Positive enthalpy of activation indicates that the reaction is endothermic and the solubility of iron ions from steel in the corrosive medium is reduced when immersion is carried out. The value of $\Delta H^{*}$ obtained is the energy needed to activate active species in the medium. The increase in activation enthalpy value is due to the formation of GLLE on the steel surface. This layer will inhibit corrosion of steel. 
The activation entropy value $\left(\Delta S^{*}\right)$ shows the degree of irregularity of the molecules in the corrosive medium. The greater the GLLE concentration added, the more positive the value of $\Delta S^{*}$. This shows that more and more extract content molecules interact with $\mathrm{Fe}^{2+}$ ions to form complex compounds. This compound will be adsorbed on the steel surface to form a passive layer which protects the surface from attacking the active species [33].

Adsorption of extracts on mild steel surfaces that form a thin protective layer has the effect of blocking further corrosion reactions. Adsorption isotherm provides basic information about the interaction between inhibitors and mild steel surfaces so that it can be used to determine the mechanism of corrosion inhibition. The method of determining adsorption isotherm was carried out using the equation of Langmuir and Freundlich adsorption isotherms.

According to Langmuir, the decrease in force between molecules with distance causes the adsorbed layer to form only one monomolecular layer. This view is generally accepted for chemisorption and for physical adsorption at low pressures and not too high temperatures. The Freundlich adsorption isotherm equation was originally proposed based on pure empirical results. However, this equation can be determined theoretically for the adsorption model where the heat of adsorption varies exponentially with surface coverage. Langmuir adsorption isotherm is expressed through equation 5:

$$
\frac{C}{\theta}=\frac{1}{K_{\text {ads }}}+C
$$

where $K_{\text {ads }}$ is the equilibrium constant of the adsorption process, $C$ is the concentration inhibitor and $\theta$ is the surface coverage. From the plot $C / \theta$ vs. $C$ in Figure 3, a straight line was obtained. Whereas Freundlich adsorption isotherm is obtained from equation 6 [34]:

$$
\log \theta=\log K_{\text {ads }}+n \log C
$$

The plot of $\log \theta$ vs. $\log C$ is a Freundlich adsorption plot for adsorption of the investigated compound, i.e. GLLE on mild steel surfaces in $1 \mathrm{M} \mathrm{HCl}$ at $303-333 \mathrm{~K}$ shown in Figure 3 also produces a straight line.

Based on the comparison of the two adsorption isotherm types, it turns out that the Freundlich adsorption isotherm is higher than the Langmuir adsorption isotherm. The coefficient of determination $\left(R^{2}\right)$ of the Freundlich adsorption isotherm model obtained is closer to 1 compared to the $R^{2}$ value of Langmuir adsorption isotherm. Thus, Freundlich adsorption isotherm is better used to characterize the adsorption mechanism GLLE to the mild steel surface $[34,35]$.

The larger $K_{\text {ads }}$ values generally indicate that the inhibitor can be absorbed strongly on the metal surface. This high value is an indicator of the ability to inhibit a good inhibitor. At a temperature of $303 \mathrm{~K}$, the largest $K_{\text {ads }}$ value revealed that GLLE has the strongest adsorption affinity on the steel surface and hence shows the best inhibitory behavior. However, when the temperature continues to increase, the $K_{\text {ads }}$ value decreases, this indicates increased corrosion which can hinder the inhibitor adsorption. 


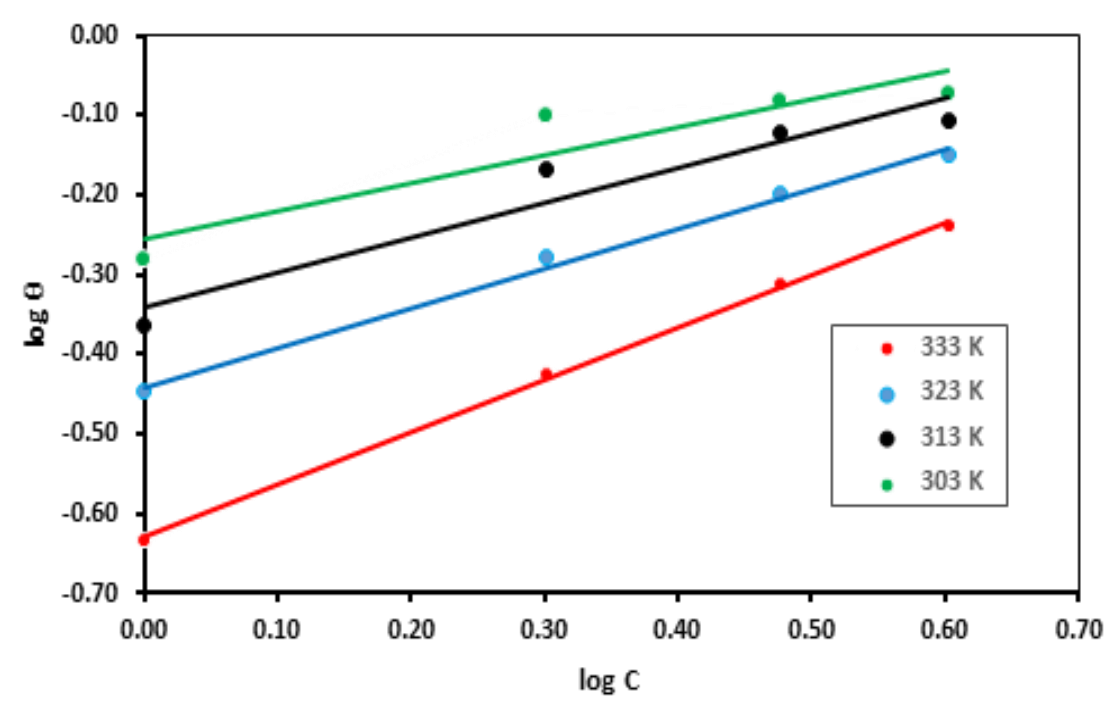

Figure 3. Freundlich adsorption isotherm for GLLE adsorption process on mild steel surfaces.

The Freundlich adsorption isotherm equation is based on the formation of a monolayer layer of GLLE molecules on mild steel surfaces. However, in the Freundlich adsorption process, the surface active parts are heterogeneous. Surface heterogeneity can be caused by the number of types of secondary metabolites contained in GLLE.

Table 5. Thermodynamic parameters for adsorption of GLLE in steel in $1 \mathrm{M} \mathrm{HCl}$ solution at each temperature based on the results of the Freundlich isotherm.

\begin{tabular}{ccccc}
\hline Temp. $(\mathbf{K})$ & $\boldsymbol{K}_{\text {ads }}$ & $\boldsymbol{\Delta} \boldsymbol{G}_{\text {ads }}(\mathbf{k J} / \mathbf{m o l})$ & $\Delta \boldsymbol{S}_{\text {ads }}(\mathbf{J} / \mathbf{m o l})$ & $\boldsymbol{\Delta} \boldsymbol{H}_{\text {ads }}(\mathbf{k J} / \mathbf{m o l})$ \\
\hline 303 & 0.56 & -8.64 & & \\
313 & 0.46 & -8.41 & & -244.93 \\
323 & 0.36 & -8.06 & & -10.16 \\
333 & 0.24 & -7.11 & & \\
\hline
\end{tabular}

From Freundlich isotherm, $\Delta G_{\text {ads }}$ value obtained is $-8.64 \mathrm{~kJ} / \mathrm{mol}$ at $303 \mathrm{~K}$ and $-7.11 \mathrm{~kJ} / \mathrm{mol}$ at $333 \mathrm{~K}$. The value obtained shows GLLE adsorption occurs spontaneously and is a physical adsorption mechanism with an adsorbed layer on mild steel surface stable enough. In general, the value of $\Delta G_{\text {ads }}$ up to $-20 \mathrm{~kJ} / \mathrm{mol}$ indicates physical adsorption while values greater than $-40 \mathrm{~kJ} / \mathrm{mol}$ indicate chemical adsorption $[34,36]$.

Heat of adsorption and adsorption entropy are important parameters for understanding organic adsorption inhibitors at the metal interface/solution. Adsorption heat $\left(\Delta G_{\text {ads }}\right)$ is calculated using the Van't Hoff equation. All of the calculated thermodynamic parameters are listed in Table 5. From the table, the negative $\Delta G_{\text {ads }}$ values are obtained, indicating that the adsorption inhibitor is an exothermic process, which means lower inhibition efficiency at high temperatures. At high temperatures, there is gradual desorption of inhibitors from mild steel surfaces. The more negative $\Delta S_{\text {ads }}$ value shows the previous behavior of inhibitor 
molecules may be free to move in the next medium inhibitor molecules become more regular when adsorbed to surface steel $[10,12]$.

\subsection{Electrochemical measurements}

Potentiodynamic polarization curves of mild steel immersed in corrosive medium $1 \mathrm{M} \mathrm{HCl}$ with existing and without GLLE are shown in Figure 4. The anodic and cathodic polarization curves in Figure 4 show differences. From the curve, it can be seen that the two cathodic and anodic curves describe a lower density of corrosion currents if there is GLLE in HCl solution. This shows this extract can block the corrosion process of mild steel. The inhibition efficiency is calculated using the following equation 7 :

$$
I E \%=\left(I_{\text {corr }}^{0}-I_{\text {corr }} / I_{\text {corr }}^{0}\right) \cdot 100
$$

where $I_{\text {corr }}^{0}$ and $I_{\text {corr }}$ are the corrosion current density values without and with GLLE inhibitor respectively.

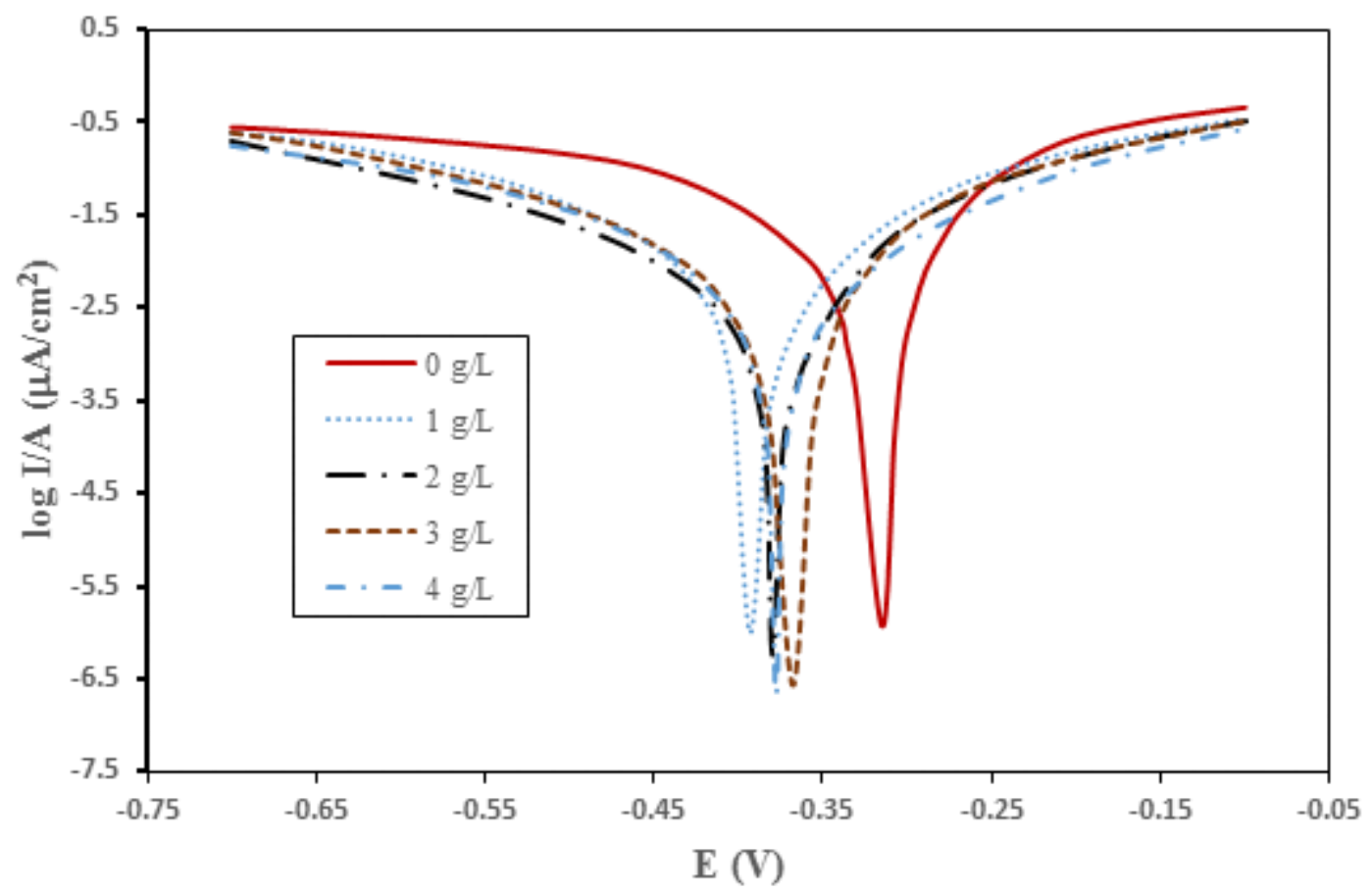

Figure 4. Tafel plots from mild steel immersed in $1 \mathrm{M} \mathrm{HCl}$ medium without and with GLLE.

Some corrosion parameters namely corrosion potential $\left(E_{\text {corr }}\right)$, corrosion current $\left(I_{\text {corr }}\right)$ and inhibition efficiency percentage calculated from the Tafel plot are given in Table 6. Data from Table 6 found an increase in GLLE concentration that was able to reduce the density of corrosion currents, which indicate that the inhibition efficiency increases with increase in the concentration of GLLE. These results are in agreement with those obtained from the weight loss method. Besides that, it can be seen that the corrosion potential shift slightly to 
more negative direction in the presence of GLLE. The largest displacement in $E_{\text {corr }}$ value observed at a concentration of $1 \mathrm{~g} / \mathrm{L}$ is $47 \mathrm{mV}$, which is much less than $85 \mathrm{mV}$. This confirms that GLLE acts as mixed-type inhibitor with cathodic dominance [37, 38].

Table 6. Corrosion potential, corrosion current and corrosion inhibition efficiency of mild steel in $1 \mathrm{M} \mathrm{HCl}$ from extrapolation of Tafel plots without and with the addition of GLLE.

\begin{tabular}{cccc}
\hline $\begin{array}{c}\text { GLLE concentration } \\
(\mathbf{g} / \mathbf{L})\end{array}$ & $\begin{array}{c}\boldsymbol{E}_{\mathbf{c o r r}} \\
(\mathbf{m V})\end{array}$ & $\begin{array}{c}\boldsymbol{I}_{\mathbf{c o r r}} \\
\left(\boldsymbol{\mu A} / \mathbf{c m}^{2}\right)\end{array}$ & $\begin{array}{c}\boldsymbol{I E} \\
(\boldsymbol{\%})\end{array}$ \\
\hline 0 & -346 & -1.564 & 0 \\
1 & -393 & -1.882 & 51.92 \\
2 & -380 & -2.227 & 80.37 \\
3 & -368 & -2.365 & 84.19 \\
4 & -378 & -2.495 & 88.28 \\
\hline
\end{tabular}

\subsection{FT-IR analysis}

Transform Fourier infrared spectrophotometry is a method used to determine the functional groups and the structure of an organic compound by comparing the fingerprint area. FT-IR analysis was carried out to determine the functional groups of secondary metabolites contained in GLLE. Compounds that have functional groups such as hydroxyl $(-\mathrm{OH})$, carboxyl $(-\mathrm{COOH})$, carbonyl $(-\mathrm{C}=\mathrm{O}),-\mathrm{CO}-, \mathrm{C}-\mathrm{H},=\mathrm{CH}_{2},-\mathrm{C}=\mathrm{C}-,-\mathrm{C} \equiv \mathrm{C}-,-\mathrm{C}-\mathrm{Cl}$, and nitrile $(-\mathrm{C} \equiv \mathrm{N})$ which has a free electron pair can form a complex on a mild steel surface. The analysis was carried out by comparing the spectrum of GLLE with a spectrum of layers adsorbed on a mild steel surface.

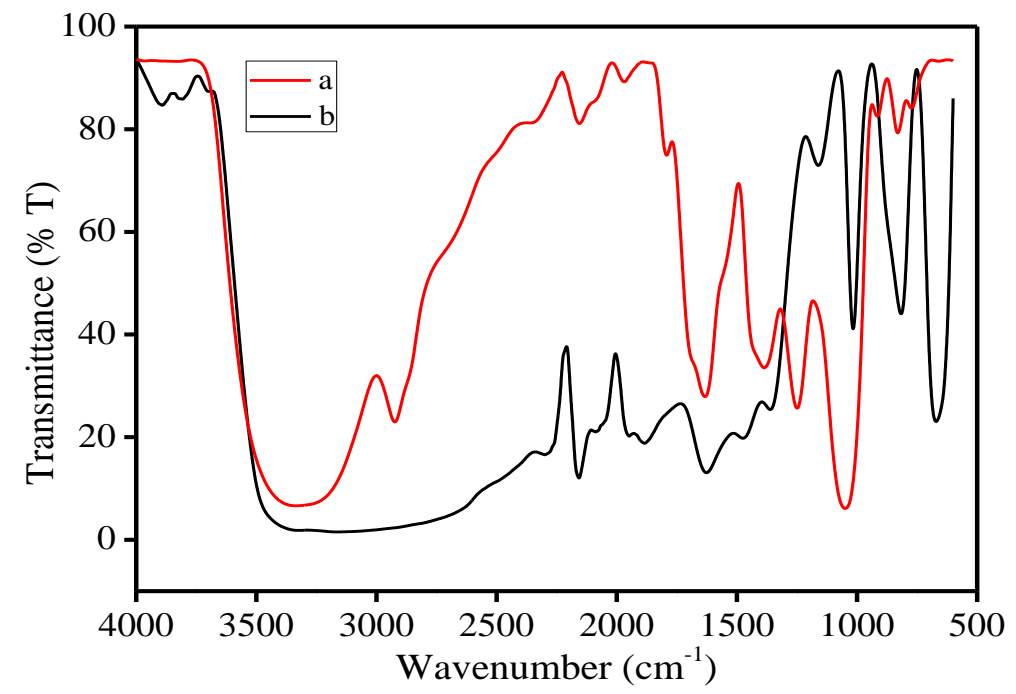

Figure 5. FT-IR spectra of GLLE (a) and extract layer corrosion product (b) which is absorbed. 
In this case, the FT-IR spectrum is used as supporting data which can declare the inhibition of corrosion of mild steel in an acid medium. This is because the GLLE inhibitor molecule is adsorbed onto the mild steel surface. In addition, the FT-IR spectrum provides information on the formation of new bonds on mild steel surface after immersion in $\mathrm{HCl}$ solution. The layer formed on the surface will prevent further corrosion by $\mathrm{HCl}$ corrosive medium against mild steel [39].

The spectrum in Figure 5(a) shows that the GLLE contains the $-\mathrm{OH}$ group with the appearance of absorption peaks at the wave number $3334.49 \mathrm{~cm}^{-1}$, the $\mathrm{C}=\mathrm{O}$ absorption peak at $1792.32 \mathrm{~cm}^{-1}$, the $\mathrm{CH}$ group at the wave number $2923.65 \mathrm{~cm}^{-1}$, and $-\mathrm{CO}-$ group at wave number $1249.21 \mathrm{~cm}^{-1}$ and $\mathrm{C}=\mathrm{C}$ group at wave number $1386.40 \mathrm{~cm}^{-1}$. The $1632.71 \mathrm{~cm}^{-1}$ bands is assigned to the $\mathrm{N}-\mathrm{H}$ bend. However in Figure 5(b) is the infrared spectrum of the corrosion products of mild steel immersed in $1 \mathrm{M} \mathrm{HCl}$ with the additional GLLE with a concentration of $4 \mathrm{~g} / \mathrm{L}$. From the two spectrums, it can be seen that there is an interaction between the components of mild steel and GLLE and adsorbed on the steel surface so that the absorption of the extract groups undergoes a shift in the wave number. The shift occurs in the absorption of the $\mathrm{O}-\mathrm{H}$ group to the wave number $3160.64 \mathrm{~cm}^{-1}$, the $\mathrm{C}=\mathrm{O}$ group to $1883.62 \mathrm{~cm}^{-1}$, the $\mathrm{CH}$ group to $2300.06 \mathrm{~cm}^{-1}$, the $\mathrm{C}=\mathrm{C}$ group to $1474.62 \mathrm{~cm}^{-1}$, and the $-\mathrm{CO}-$ group to wave number $1361.19 \mathrm{~cm}^{-1}$. The wave number identified as $\mathrm{N}-\mathrm{H}$ bending shifts found to the shift to $1634.64 \mathrm{~cm}^{-1}$ on the adsorbed film of GLLE spectrum. The shift from absorption bands to higher frequency areas indicates that there is an interaction on the steel surface $[19,36]$.

\subsection{Surface analysis}

The characterization of mild steel surfaces using scanning electron microscopy (SEM) is one of the methods to prove the effect of resilient GLLE in the hydrochloric acid corrosive medium changes in corrosion rate. The mild steel surface soaked in $1 \mathrm{M} \mathrm{HCl}$ medium and GLLE looks smoother on the surface without much corrosion. The scanning electron microscopy of the mild steel surface is shown in Figure 6(a) shows that the surface morphology of the steel that has been cleaned, and the surface is considerably quite good and even.

At that time, the steel still had no surface interaction with the $\mathrm{HCl}$ corrosive medium. Figure 6(b) shows a mild steel surface morphology that has been immersed in $1 \mathrm{M} \mathrm{HCl}$ medium for six days. Mild steel surface undergoes a corrosion process, which is indicated by the appearance of steel surface damage, which results in mild steel surfaces becoming rough and uneven. Next, Figure 6(c) displays a mild steel surface morphology immersed in $1 \mathrm{M} \mathrm{HCl}$ medium with the addition of $4 \mathrm{~g} / \mathrm{L}$ GLLE. The steel surface is smoother and flatter than mild steel in a $1 \mathrm{M} \mathrm{HCl}$ solution. The thin layer of the compounds in GLLE is adsorbed on the mild steel surface and serves to prevent the corrosion process. 


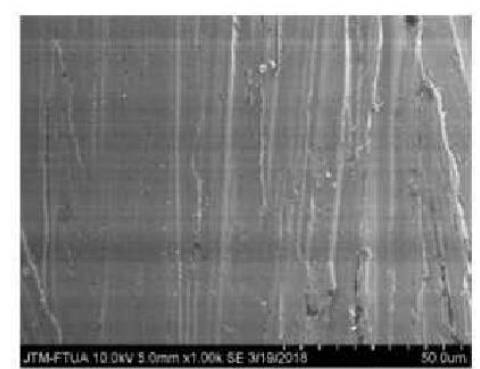

(a)

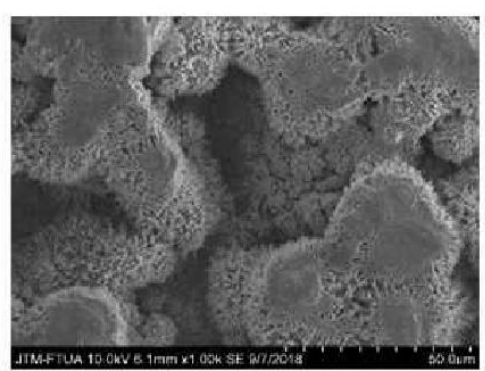

(b)

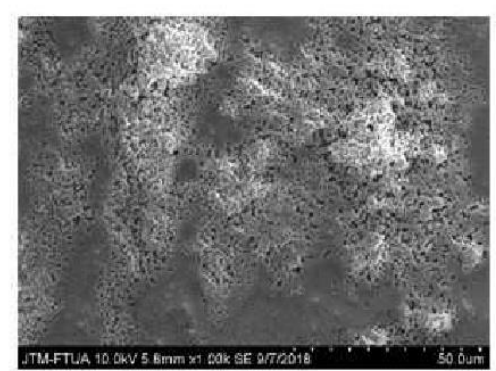

(c)

Figure 6. Micrograph scanning electron microscopy (SEM) mild steel surface (a), mild steel in $1 \mathrm{M} \mathrm{HCl}$ (b) and mild steel in $1 \mathrm{M} \mathrm{HCl}$ solution $+4 \mathrm{~g} / \mathrm{L} \mathrm{GLLE} \mathrm{(c).}$

\section{Conclusion}

The Gleichenia linearis Burm. leaf extract (GLLE) contains natural ingredients with high potential to be used as a mild steel corrosion inhibitor in hydrochloric acid medium. The value of inhibition efficiency is relatively high, even though the extract concentration reaches $4 \mathrm{~g} / \mathrm{L}$. The corrosion rate of mild steel decreases with increasing GLLE in the hydrochloric acid medium and increases with increasing temperature. The adsorption of GLLE on mild steel surfaces inhibits corrosion rates follows the Freundlich adsorption isotherm model. Adsorption occurs spontaneously, and the corrosion inhibition of GLLE occurs due to the physical adsorption process on the steel surface. Potentiodynamic polarization measurements showed that GLLE was a type of mixed inhibitor with more cathodic effectiveness. FT-IR analysis revealed a shift in the absorption band, which indicated an interaction between GLLE and mild steel surface. Characterization using SEM showed differences in the morphology of mild steel before and after immersion in corrosive medium $(1 \mathrm{M} \mathrm{HCl})$ with and without the addition of GLLE.

\section{Acknowledgement}

All authors acknowledge the financial support from FMIPA Universitas Andalas for Doctor Dissertation Research contract no. 11/UN.16.03.D/PP/FMIPA/2018, Financial Year 2018.

\section{References}

1. Emriadi, A. Santoni and Y. Stiadi, Adsorptive and thermodynamic properties of methanol extract of Toona sinensis leaves for the corrosion of mild steel in $\mathrm{HCl}$ medium, Pharma Chem., 2016, 8, no. 18, 266-273.

2. A. Ostovari, S.M. Hoseinieh, M. Peikari, S.R. Shadizadeh and S.J. Hashemi, Corrosion inhibition of mild steel in $1 \mathrm{M} \mathrm{HCl}$ solution by henna extract: A comparative study of the inhibition by henna and its constituents (Lawsone, Gallic acid, a-D-Glucose and Tannic acid), Corros. Sci., 2009, 51, 1935-1949. doi: 10.1016/j.corsci.2009.05.024 
3. A. Ehsani, M.G. Mahjani, M. Hosseini, R. Safari, R. Moshrefi and H.M. Shiri, Evaluation of Thymus vulgaris plant extract as an eco-friendly corrosion inhibitor for stainless steel 304 in acidic solution by means of electrochemical impedance spectroscopy, electrochemical noise analysis and density functional theory, J. Colloid Interface Sci., 2017, 490, 444-451. doi: 10.1016/j.jcis.2016.11.048

4. N. M'hiri, D. Veys-Renaux, E. Rocca, I. Ioannou, N.M. Boudhrioua and M. Ghoul, Corrosion inhibition of carbon steel in acidic medium by orange peel extract and its main antioxidant compounds, Corros. Sci., 2016, 102, 55-62. doi: 10.1016/j.corsci.2015.09. $\underline{017}$

5. S.A. Umoren, I.B. Obot, A.U. Israel, P.O. Asuquo, M.M. Solomon, U.M. Eduok and A.P. Udoh, Inhibition of mild steel corrosion in acidic medium using coconut coir dust extracted from water and methanol as solvents, J. Ind. Eng. Chem., 2014, 20, 36123622. doi: $10.1016 /$ j.jiec.2013.12.056

6. H.H. Abdel-Rahman, A.M. Hafez and A.A. Helmy, Physicochemical Study on the Effectiveness of co-Friendly Anti-Corrosion Agent on the Corrosion of Steel in $\mathrm{H}_{3} \mathrm{PO}_{4}$ solution, Electrochemistry, 2015, 83, no. 6, 440-444. doi: 10.5796/electrochemistry.83. $\underline{440}$

7. A.M. Al-Turkustani, Thermodynamic, chemical and electrochemical investigation of Pandanus tectorius extract as corrosion inhibitor for steel in sulfuric acid solutions, Eur. J. Chem., 2013, 4, no. 3, 303-310. doi: 10.5155/eurjchem.4.3.303-310.805

8. M. Chellouli, D. Chebabe, A. Dermaj, H. Erramli, N. Bettach, N. Hajjaji, M.P. Casaletto, C. Cirrincione, A. Privitera and A. Srhiric, Corrosion inhibition of iron in acidic solution by a green formulation derived from Nigella sativa L, Electrochim. Acta, 2016, 204, 5059. doi: 10.1016/j.electacta.2016.04.015

9. E.E. Oguzie, Evaluation of the inhibitive effect of some plant extracts on the acid corrosion of mild steel, Corros. Sci., 2008, 50, 2993-2998. doi: 10.1016/j.corsci.2008. $\underline{08.004}$

10. S. Muthumanickam, B. Jeyaprabha, R. Karthik, A. Elangovan and P. Prakash, Adsorption and corrosion inhibiting behavior of Passiflora foetida leaf extract on mild steel corrosion, Int. J. Corros. Scale Inhib., 2015, 4, no. 4, 365-381. doi: 10.17675/23056894-2015-4-4-6

11. A.E.S. Fouda, A.A. Nazeer, A.Y. El-Khateeb and M. Fakih, Cinnamon plant extract as corrosion inhibitor for steel used in waste water treatment plants and its biological effect on Escherichia coli, J. Korean Chem. Soc., 2014, 58, no. 4, 359-365. doi: 10.5012/jkcs.2014.58.4.359

12. Y. Qiang, S. Zhang, B. Tan and S. Chen, Evaluation of Ginkgo leaf extract as an ecofriendly corrosion inhibitor of X70 steel in $\mathrm{HCl}$ solution, Corros. Sci., 2018, 133, 6-16. doi: $10.1016 / j . c o r s c i .2018 .01 .008$

13. D.R. Gusti, Emriadi, A. Alif and M. Efdi, Corrosion inhibition of ethanol extract of cassava (Manihot esculenta) leaves on mild steel in sulfuric acid, Int. J. ChemTech Res., 2017 , 10, no. 2, 163-171. 
14. E.A. Noor, Temperature Effects on the Corrosion Inhibition of Mild Steel in Acidic Solutions by Aqueous Extract of Fenugreek Leaves, Int. J. Electrochem. Sci., 2007, 2, 996-1017.

15. I.E. Uwah, P.C. Okafor and V.E. Ebiekpe, Inhibitive action of ethanol extracts from Nauclea latifolia on the corrosion of mild steel in $\mathrm{H}_{2} \mathrm{SO}_{4}$ solutions and their adsorption characteristics, Arabian J. Chem., 2013, 6, 285-293. doi: 10.1016/j.arabjc.2010.10.008

16. J. Bhawsar, P.K. Jain and P. Jain, Experimental and computational studies of Nicotiana tabacum leaves extract as green corrosion inhibitor for mild steel in acidic medium, Alexandria Eng. J., 2015, 54, 769-775. doi: 10.1016/j.aej.2015.03.022

17. G.M. Al-Senani, Corrosion Inhibition of Carbon Steel in Acidic Chloride Medium by Cucumis sativus (Cucumber) Peel Extract, Int. J. Electrochem. Sci., 2016, 11, 291-302.

18. J.C. da Rocha, J.A.C.P. Gomes and E. D'Elia, Corrosion inhibition of carbon steel in hydrochloric acid solution by fruit peel aqueous extracts, Corros. Sci., 2010, 52, 23412348. doi: $10.1016 /$ j.corsci.2010.03.033

19. S.A.F. Ramos, L.F. de Senna and D.C.B. do Lago, Evaluation of aqueous coffee husks extracts as a corrosion inhibitor of 1020 carbon steel in $1 \mathrm{~mol} \mathrm{~L}^{-1} \mathrm{HCl}$ solution, Mater. Res., 2019, 22, 1-9. doi: 10.1590/1980-5373-mr-2018-0839

20. G. Ji, S. Anjum, S. Sundaram and R. Prakash, Musa paradisica peel extract as green corrosion inhibitor for mild steel in HCl solution, Corros. Sci., 2015, 90, 107-117. doi: 10.1016/j.corsci.2014.10.002

21. Y. Yetri, Emriadi, N. Jamarun and Gunawarman, Inhibitory Action of Theobroma cacao Peels Extract on Corrosion of Mild Steel in Different Media, Rasayan J. Chem., 2016, 9, no. 4, 716-727.

22. L.S. Barreto, M.S. Tokumoto, I.C. Guedes, H.G. de Melo, F. Amado and V.R. Capelossi, Study and Assessment of the Efficiency of the Cocoa Bark Extracted from the Theobroma cacao as an Inhibitor of the Corrosion of Carbon Steel in Substitution of Benzotriazole, Mater. Res., 2018, 21, no. 1, 1-9. doi: 10.1590/19805373-mr-2016-0309

23. N.E. Hamdani, R. Fdil, M. Tourabi, C. Jama and F. Bentiss, Alkaloids extract of Retama monosperma (L.) Boiss. seeds used as novel eco-friendly inhibitor for carbon steel corrosion in $1 \mathrm{M} \mathrm{HCl}$ solution: Electrochemical and surface studies, Appl. Surf. Sci., 2015, 357, 1294-1305. doi: 10.1016/j.apsusc.2015.09.159

24. K.P.V. Kumar, M.S.N. Pillai and G.R. Thusnavis, Seed Extract of Psidium guajava as Ecofriendly Corrosion Inhibitor for Carbon Steel in Hydrochloric Acid Medium, J. Mater. Sci. Technol., 2011, 27, no. 12, 1143-1149. doi: 10.1016/S1005-0302(12)60010-3

25. V.S. Priya, A.A.F. Sabirneeza and S. Subhashini, Inhibition of Mild Steel Corrosion in Sulphuric Acid Using Ceiba pentandra Seed Extract, Int. J. Curr. Res., 2014, 6, no. 5, 6571-6575.

26. A. Singh, V.K. Singh and M.A. Quraishi, Inhibition Effect of Environmentally Benign Kuchla (Strychnos nuxvomica) Seed Extract on Corrosion of Mild Steel in Hydrochloric Acid Solution, Rasayan J. Chem., 2010, 3, no. 4, 811-824. 
27. M. Barrahi, H. Elhartiti， A. El Mostaphi, N. Chahboun, M. Saadouni, R. Salghi, A. Zarrouk and M. Ouhssine, Corrosion inhibition of mild steel by Fennel seeds (Foeniculum vulgare Mill) essential oil in $1 \mathrm{M}$ hydrochloric acid solution, Int. J. Corros. Scale Inhib., 2019, 8, no. 4, 937-953. doi: 10.17675/2305-6894-2019-8-4-9

28. C.O. Akalezi, C.E. Ogukwe, E.A. Ejele and E.E. Oguzie, Mild steel protection in acidic media using Mucuna pruriens seed extract, Int. J. Corros. Scale Inhib., 2016, 5, no. 2, 132-146. doi: 10.17675/2305-6894-2016-5-2-3

29. Y. Stiadi, Rahmayeni, L. Rahmawati, M. Efdi, H. Aziz and Emriadi, Mangifera odorata Griff Seed Extract as Corrosion Inhibitor of Mild Steel in Hydrochloric Acid Medium, Rasayan J. Chem., 2020, 13, no. 1, 230-239. doi: 10.31788/RJC.2020.1315325

30. S. Deng and X. Li, Inhibition by Jasminum nudiflorum Lindl. leaves extract of the corrosion of aluminium in $\mathrm{HCl}$ solution, Corros. Sci., 2012, 64, 253-262. doi: 10.1016/j.corsci.2012.07.017

31. N. Soltani, N. Tavakkoli, M.K. Kashani, A. Mosavizadeh, E.E. Oguzie and M.R. Jalali, Silybum marianum extract as a natural source inhibitor for 304 stainless steel corrosion in 1.0 M HCl, J. Ind. Eng. Chem., 2014, 20, 3217-3227. doi: 10.1016/j.jiec.2013.12.002

32. P.B. Raja, A.K. Qureshi, A.A. Rahim, H. Osman and K. Awang, Neolamarckia cadamba alkaloids as eco-friendly corrosion inhibitors for mild steel in $1 \mathrm{M} \mathrm{HCl}$ media, Corros. Sci., 2013, 69, 292-301. doi: 10.1016/j.corsci.2012.11.042

33. P. Muthukrishnan, B. Jeyaprabha and P. Prakash, Adsorption and corrosion inhibiting behavior of Lannea coromandelica leaf extract on mild steel corrosion, Arabian J. Chem., 2017, 10, S2343-S2354. doi: 10.1016/j.arabjc.2013.08.011

34. A.S. Fouda, M. Abdallah, I.S. Ahmed and M. Eissa, Corrosion inhibition of aluminum in $1 \mathrm{M} \mathrm{H}_{3} \mathrm{PO}_{4}$ solutions by ethanolamines, Arabian J. Chem., 2012, 5, no. 3, 297-307. doi: $10.1016 /$ j.arabjc.2010.08.020

35. B. Meroufel, O. Benali, M. Benyahia, Y. Benmoussa and M.A. Zenasni, Adsorptive removal of anionic dye from aqueous solutions by Algerian kaolin: Characteristics, isotherm, kinetic and thermodynamic studies, J. Mater. Environ. Sci., 2013, 4, no. 3, $482-491$.

36. A. Prithiba and R. Rajalakshmi, An ecofriendly initiative for the corrosion inhibition of mild steel in $1 \mathrm{M} \mathrm{HCl}$ using Tecoma capensis flower extract, Int. J. Met., 2016, 1-11. doi: $10.1155 / 2016 / 8579429$

37. Y. Yan, W. Li, L. Cai and B. Hou, Electrochemical and quantum chemical study of purines as corrosion inhibitors for mild steel in $1 \mathrm{M} \mathrm{HCl}$ solution, Electrochim. Acta, 2008, 53, no. 20, 5953-5960. doi: 10.1016/j.electacta.2008.03.065

38. H. Bentrah, Y. Rahali and A. Chala, Gum Arabic as an eco-friendly inhibitor for API 5L X42 pipeline steel in $\mathrm{HCl}$ medium, Corros. Sci., 2014, 82, 426-431. doi: $\underline{10.1016 / j . c o r s c i .2013 .12 .018 ~}$ 
39. S.A. Umoren, U.M. Eduok, M.M. Solomon and A.P. Udoh, Corrosion inhibition by leaves and stem extracts of Sida acuta for mild steel in $1 \mathrm{M} \mathrm{H}_{2} \mathrm{SO}_{4}$ solutions investigated by chemical and spectroscopic techniques, Arabian J. Chem., 2016, 9, S209-S224. doi: $\underline{10.1016 / j . a r a b j c .2011 .03 .008}$ 